\title{
Association between Metabolic Disturbances and G-174C Polymorphism of Interleukin-6 Gene in Obese Children
}

\author{
B. Pyrzak ${ }^{1}$, A. Wisniewska' ${ }^{1}$ A. Majcher ${ }^{1}$, K. Popko², M. Wasik ${ }^{2}$, U. Demkow ${ }^{2}$ \\ ${ }^{1}$ Department of Pediatrics and Endocrinology and ${ }^{2}$ Department of Laboratory Diagnostics and Clinical Immunology of \\ Developmental Age, Warsaw Medical University, Warsaw, Poland
}

\begin{abstract}
Objective: The aim of the study was to investigate whether the G-174C polymorphism of the IL-6 gene is related to obesity and the incidence of the metabolic syndrome (MetS) according to IDF definition in children.

Materials and methods: The examined group included 124 obese children with BMI $\geq 2$ SDS, and the control group consisted of 56 non-obese children with BMI $<1.0$ SDS. Polymorphism identification was performed in total genomic DNA using PCR-RFLP method.

Results: In the obese children, carriers of $\mathrm{C}$ allele in homozygotic and heterozygotic genotypes were more frequent than in the control group. The carriers of $\mathrm{C}$ alleles presented with lower thickness of subcutaneous tissue and higher concentrations of HDL-C than the wild type. The incidence of MetS was $33 \%$ of the group of obese children. Analysis of the presence of MetS factors showed that there is more frequent MetS in the group with the wild homozygous genotype type. Conclusion: Polymorphism 174G $>C$ in the IL-6 gene does not seem to be associated with obesity and with the incidence of MetS in children.
\end{abstract}

Key words: interleukin-6, polymorphism, obesity, children, metabolic syndrome

\section{INTRODUCTION}

Untreated pediatric obesity frequently leads to severe metabolic and cardiovascular complications. Obesity has been strongly associated with insulin resistance, and is considered as an important independent risk factor for cardiovascular diseases [1].

A number of studies confirmed increasing prevalence of obesity in children and adolescents [2]. There is a great deal of evidence that in the pathogenesis of insulin resistance, apart from environmental factors such as body weight, age, physical activity, or a diet, a key role is played by genetic predisposition [3]. Serious consequences accompanying obesity may be caused by increased concentrations of proinflammatory cytokines, e.g., IL-1, IL-6, and TNF, and the association with their gene polymorphisms was found in several studies [4].

IL-6 is now well recognized for its role in the acute phase of inflammatory response which is characterized by production of a variety of hepatic proteins known as acute phase proteins (e.g., C-reactive pro- tein, serum amyloid A, fibrinogen, complement, and alpha1-antitrypsin). It is known that IL-6 plays an important role in lipid metabolism and energy expenditure [5]. Plasma concentration of IL-6 is increased in obese and insulin resistant subjects [6]. Persistent systemic increase of IL-6 in chronic inflammatory states such as obesity and type 2 diabetes may trigger insulin resistance, whereas transient increase may contribute to normal glucose homeostasis. IL- 6 modulates insulin resistance through several distinct mechanisms, including c-Jun N-terminal kinase 1 (JNK1)-mediated serine phosphorylation of IRS-1-insulin receptor substrate-1, IкB kinase (IKK)-mediated nuclear factor- $\kappa \mathrm{B}$ (NF-KB) activation, and induction of SOCS-3-suppressor of cytokine signaling family 3 [7].

The concentration of interleukin- 6 is affected by the polymorphism found in point 174 (G174C) of a promoter region of IL- 6 gene. Previous studies have shown that the presence of $\mathrm{C}$ allele in the promoter region of IL-6 gene is also associated with a higher probability of overweight and obesity [8]. Studies of the biological relevance of the IL-6 G-174C promoter polymorphism have indicated that the presence of $\mathrm{C}$ allele seems to result in a lower IL- 6 gene expression than the $G$ allele. That suggests that the mean IL-6 concentrations might be lower in subjects with the homozygous CC genotype [9]. However, conflicting data exist regarding the associations between common variations in the IL- 6 gene, adiposity, and insulin resistance [10]. The purpose of the present study was to evaluate the frequency of the IL-6 G-174C polymorphism in obese children in relation to the presence of insulin resistance, leptin level, lipid abnormalities, and the incidence of the metabolic syndrome.

\section{Materials AND Methods}

The study protocol was approved by the Research and Ethics Committee of the Medical University of Warsaw in Poland. The examined group included 124 obese children with simple obesity ( 72 girls and 52 boys) aged $10-18$ (mean age 14.6 years) referred to an outpatient endocrinology clinic. The control group consisted of 56 healthy non-obese children (36 girls and 20 boys) aged 11-18 years (mean age 14). A complete history was obtained and physical examination was carried out in all participants. Height, weight, and blood pressure were routinely measured. Body mass 
index (BMI) was calculated as $\mathrm{kg} / \mathrm{m}^{2}$, BMI $\mathrm{z}$-score adjusted for age and sex was calculated using normative data. Obesity was defined as a BMI z-score of more than +2 . Waist circumference was adjusted for age and sex and referred to percentile charts. Hip circumference, WHR (waist-to-hip ratio) and the sum of the thickness of 3 and 10 skin-folds were measured. The percentage of fat tissue content measured in skinfolds on the arm and below the shoulder blade was calculated using Slaughter's equation [11]. Hypertension was defined as a value of systolic and/or diastolic blood pressure $\geq 95$ th percentile for sex and age. Prehypertension was defined as a value of systolic and/or diastolic blood pressure between the 90-95th percentile.

\section{Biochemical Tests}

Oral glucose tolerance test (OGTT) with measurements of glucose and insulin was performed with the use of a standard dose of glucose $(1.75 \mathrm{~g} / \mathrm{kg}$, max 75 $\mathrm{g})$ in the group of obese children. The insulin concentration was measured by RIA (Radio-Immuno-Assay), plasma glucose level was measured using dry-chemistry method. Hyperinsulinemia was recognized if fasting levels of insulin was greater than $15 \mu \mathrm{IU} / \mathrm{ml}$ or insulin peak (post-OGTT) levels was of more than 150 $\mu \mathrm{IU} / \mathrm{ml}$ and/or more than $75 \mu \mathrm{U} / \mathrm{ml}$ at $120 \mathrm{~min}$ of OGTT [12]. Insulin resistance was estimated using the fasting plasma insulin homeostasis model assessment HOMA.

Plasma total cholesterol (T-chol) and triglycerides ( $\mathrm{Tg}$ ) were determined enzymatically wth a Hitachi 912 analyzer (Roche Diagnostics). HDL-cholesterol (HDL-C) was measured using a homogenous method with polyethylene glycol-modified enzymes and alphacyclodextrin. LDL-cholesterol (LDL-C) was calculated by the Friedewald equation. The total cholesterol ( $\mathrm{T}$ chol) $>200 \mathrm{mg} / \mathrm{dl}$, triglycerides (TG) $>130 \mathrm{mg} / \mathrm{dl}$, LDL-cholesterol $>150 \mathrm{mg} / \mathrm{dl}$ concentrations were set as the upper limit, high-density lipoprotein cholesterol (HDL-C) $<45 \mathrm{mg} / \mathrm{dl}$ was defined as the lower limit for boys and $<50 \mathrm{mg} / \mathrm{dl}$ for girls. A leptin concentration measured by RIA (Radio-Immuno-Assay) was referred to the reference value of $15-20 \mathrm{ng} / \mathrm{dl}$ [13]. The International Diabetes Federation (IDF) criteria for children and adolescence were used to evaluate the incidence of the metabolic syndrome (MetS) [14].

\section{Genetic Tests}

Genetic blood tests were performed in both study and control groups. Genotyping was done using polymerase chain reaction - restriction fragment length polymorphism analyses. Genomic DNA was amplified with specific flanking primers for IL-6 174 G/C. The primers used in the PCR were: forward 5' TGACTTCAGCT'TTACTCT'T'TGT 3' and reverse 5' CTGATTGGAAACCTTATTAAG 3'. The amplified PCR product was digested with the addition Sfa NI enzymes. The digested samples were separated by electrophoresis and visualized. The identified genotypes were recognized according to the presence or absence of the enzyme restriction sites.

\section{STATISTICAL ANALYSIS}

Results were presented as means $\pm \mathrm{SD}$, minimum, and maximum. The normality of data distribution was assessed by the Shapiro-Wilk test. Student's t-test for independent and non-independent samples was used to determine the statistical difference between genders in mean values for each group. Pearson's $\chi^{2}$ test was used to examine differences in characteristic variables and the distribution of genetic polymorphism between the study and control groups. In children with the metabolic syndrome in the obese group, the odds ratio (OR) and $95 \%$ confidence interval $(95 \% \mathrm{CI})$ were evaluated to estimate the associations between the children with wild homozygous and carriers $C$ alleles. The U test 'for a probability' was used to compare the carriers of $\mathrm{C}(\mathrm{CC}+\mathrm{GC})$ alleles between the obese and control groups. Results were processed using Statgraphics 4.0 plus and STATISTICA 6.0 software. Statistical significance was accepted at a level of $\mathrm{P}<0.05$ [15]. The Hardy-Weinberg equilibrium test was applied to evaluate genotype frequencies [16].

\section{RESULTS}

Anthropometric and metabolic characteristics of the obese children are presented in Table 1. The axiological evaluation showed significantly higher values in the obese of all examined parameters in comparison with the reference values for age and sex. SDS waist circumference, considered to be one of the most important elements of the metabolic syndrome, was higher than the reference values across the whole study group (above $90^{\text {th }}$ percentile in $89 \%$ girls and in 100\% of boys).

The metabolic syndrome (MetS): central obesity $(100 \%$ of obese children presented with waist circumference $>90^{\text {th }}$ percentile), low HDL-C (58\% of obese children), hypertriglyceridemia ( $45 \%$ of obese children), hypertension ( $47 \%$ of obese children), impaired fasting glucose (IFG $-2.4 \%$ of obese children). Two children had diabetes type 2 . The incidence of the full MetS (central obesity plus 2 or more abnormalities) was $33 \%$ of obese children (20 girls $-16.1 \%$ and 21 boys - $16.9 \%$ ).

Frequency distribution analysis of polymorphism G-174C in the obese and non-obese children is presented in Fig. 1. The alleles $C$ and $G$ in both obese and control groups are in HW equilibrium. Homozygous allele CC in the obese children was statistically more frequent than in the control group (OR $=3.57 ; 95 \%$ $\mathrm{CI}=1.01-12.56), \chi^{2}=5.02, \mathrm{P}<0.05$. Heterozygotes of $\mathrm{C}$ allele in the obese children were significantly more frequent than in the control group (OR $=2.56$; $95 \%$ $\mathrm{CI}=1.33-4.91), \chi^{2}=8.08, \mathrm{P}<0.01$.

The obese children were divided into two groups, with and without allele C, on the basis of the IL- 6 genotypes. The carriers of $\mathrm{C}$ alleles $(\mathrm{CG}+\mathrm{CC})$ presented with lower thickness of subcutaneous tissue calculated as a sum of 10 skin-folds $(164.7 \pm 23.8$ vs. $177.0 \pm 33.4 \mathrm{~mm}, \mathrm{P}<0.05)$ than the wild type gene carriers. The carriers of $\mathrm{C}$ alleles also showed higher concentrations of HDL-C compared to GG homozygotes $(50.5 \pm 12.7$ vs. $44.0 \pm 10.8 \mathrm{mg} / \mathrm{dl}, \mathrm{P}<0.05)$. The systolic blood pressure and leptin concentration 
Table 1. Anthropometric and metabolic characteristics of the obese children.

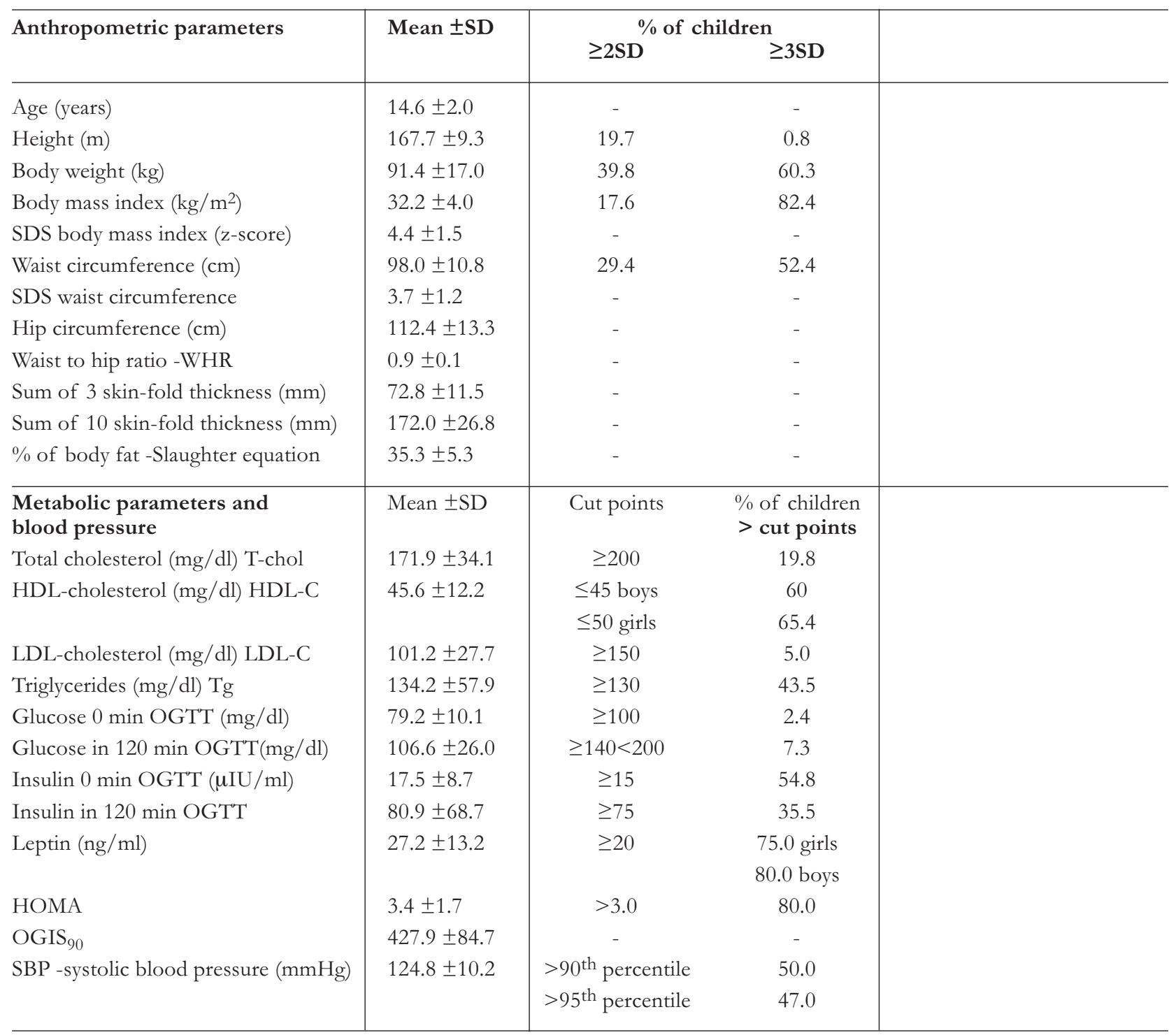

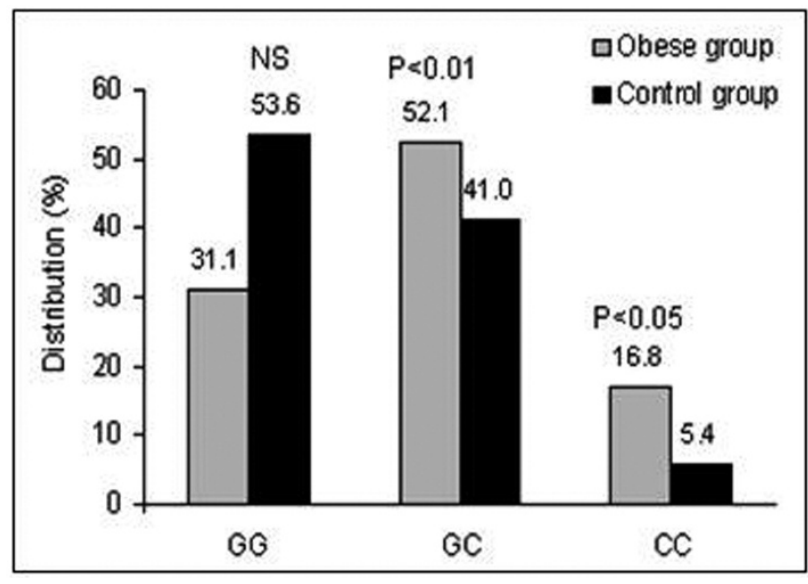

Fig 1. Distribution of IL-6 genotypes in obese children vs. control group.

did not differ between the obese children with gene polymorphism and wild homozygous. There was only a tendency seen toward a lower value of leptin levels in the children with GG genotype. In the group of obese boys carrying $\mathrm{C}$ allele, a sum of 3 skin-fold thickness was lower than those with the GG genotype $(170.2 \pm 25.7$ vs. $190.4 \pm 41.4 \mathrm{~mm}, \mathrm{P}<0.05)$. The presence of the metabolic syndrome in children with wild homozygous GG and carriers of C allele of IL6 polymorphism gene was more frequent in the group with wild GG genotype than in the children carrying $\mathrm{C}$ allele (GC+CC) $\quad\left(\mathrm{OR}=0.32 ; 95 \%\right.$ CI $0.14-0.75 \chi^{2}$ $=7.11, \mathrm{P}<0.01)$. Comparison between the children carrying $C$ allele $(C G+C C)$ and carriers of the wild type genotype shows that there was a higher frequency of $\mathrm{C}$ allele in the obese children than in the control group $(\mathrm{P}<0.001)$. The presence of $\mathrm{C}$ allele was also more frequent in the obese children without MetS than in the control $(\mathrm{P}<0.001)$ and in the obese children without than with MetS $(\mathrm{P}<0.01)$. The distribution of $\mathrm{C}$ alleles in the control vs. obese children with MetS was not statistically different.

\section{DisCUSSION}

The prevalence of the metabolic syndrome is high among obese children and adolescents and increases 
with the severity of obesity and with central adiposity, in particular. The MetS clusters cardiometabolic risk factors - including abdominal obesity, hyperglycemia, dyslipidemia, and elevated blood pressure - that are thought to be linked to insulin resistance. MetS is also associated with increased risk for cardiovascular disease and type 2 diabetes. MetS is common, affecting a quarter to a third of adults population in developed countries, and its prevalence is rising, in parallel with increasing obesity and population aging [17]. The International Diabetes Federation proposed a global definition for children and adolescents that emphasized the importance of central adiposity [14]. The metabolic syndrome phenotype is less well understood in children than in adults. Abnormalities such as obesity, hypertension, and lipid derangements are known to persist from childhood to adulthood, and the collected abnormalities may similarly persist [18]. Increasing evidence suggests that low-grade inflammation, elevated plasma, and adipose tissue levels of IL- 6 could be one of the determinants in the pathogenesis of insulin resistance and type 2 diabetes [19]. The identification of the $\mathrm{C}-174 \mathrm{G}$ polymorphism in the promoter of IL-6 gene, which regulates its transcriptional activity [9], makes this variant a credible candidate for association with insulin resistance. Some studies have shown that the $-174 \mathrm{C}$ allele may affect gene expression [8] and in vivo inflammatory response [20].

Since insulin resistance is a pivotal factor in the development of metabolic syndrome and impaired glucose tolerance (IGT), we aimed to test the association between the C-174 promoter polymorphism of the IL-6 gene variants and obesity, insulin resistance, lipids, and MetS in obese children and adolescents. Qi $\mathrm{L}$ et al [10] conducted a meta-analysis on the associations between polymorphism 174G $>\mathrm{C}$ and adiposity. In some studies polymorphism $174 \mathrm{G}>\mathrm{C}$ was associated with BMI and central adiposity [21], but not in some other [22]. Qi L et al. [10] conclude that: IL-6 variations are associated with BMI and waist circumference. Given the temporal relationship between genetic variants and adiposity phenotypes, their findings suggest that the genotype-associated changes in IL-6 could be involved in the development of obesity. It has been suggested that more than one polymorphic site in the IL- 6 gene may be functional and influence gene transcription, probably through complex interactions [23] . IL-6 polymorphism has also been associated with body composition in children. Dedoussis et al. [24] conclude that homozygotes with polymorphism of the IL- 6 gene have higher values in some parameters associated with obesity.

The results of the present study are controversial. Homozygous CC genotypes in the obese group were more frequent than in the control group. Carriers of $\mathrm{C}$ allele in the obese group also were more frequent than in the control group, but we showed that children carrying an unfavorable genotype were more protected from developing fat accumulation and lipid abnormalities. Obese children carrying the $\mathrm{C}$ allele had a smaller thickness of subcutaneous tissue measured by the sum of 10 skin-folds and they showed a tendency for higher concentrations of HDL compared with the carriers of GG allele. A new definition used by the IDF re- quires the presence of central obesity and two of the four factors. In our study of 124 children, according to this definition, $33 \%$ of them presented with the full metabolic syndrome. A comparison of appearance of metabolic syndrome factors in individuals with the CC and GC genotypes and of the homozygous GG carriers showed that the metabolic syndrome was more frequent in the group with wild homozygous that in children carrying the unfavorable genotype. These findings indicate that children carrying the $\mathrm{C}$ allele were more protected against the metabolic syndrome than children without polymorphism.

In conclusion, (i) polymorphism $174 \mathrm{G}>\mathrm{C}$ in IL-6 gene is more common in children with obesity; (ii) polymorphism $174 \mathrm{G}>\mathrm{C}$ in IL-6 gene does not seem to be associated with a grade of obesity, insulin resistance, lipid profile, leptin levels, and incidence of metabolic syndrome in obese children; and (iii) single polymorphism $174 \mathrm{G}>\mathrm{C}$ in IL-6 gene may play a protective role against development of obesity and MetS in children.

Conflicts of interest: No conflicts of interest were declared in relation to this article.

\section{REFERENCES}

[1] Bastard JP, Maachi M, Lagathu C, et al. Recent advances in the relationship between obesity, inflammation, and insulin resistance. Eur Cytokine Netw 2006; 17: 4-12.

[2] Dietz WH, Robinson TN. Overweight children and adolescents. N Engl J Med 2005; 352: 2100-2109.

[3] Barsh GS, Farooqi IS, O'Rahilly S. Genetics of bodyweight regulation. Nature 2000; 404: 644-651.

[4] Popko K, Gorska E, Potapinska O, et al. Frequency of distribution of inflammatory cytokines IL-1, IL-6 and TNF- $\alpha$ gene polymorphism in patients with obstructive sleep apnea. J Physiol Pharmacol 2008; 59 Suppl 6: 607614.

[5] Chabowski A, Zmijewska M, Gorski J, et al. Effect of IL6 deficiency on myocardial expression of fatty acid transporters and intracellular lipid deposits. J Physiol Pharmacol 2007; 58 Suppl 5: 73-82.

[6] Kern PA, Ranganathan S, Li C, Wood L, Ranganathan G. Adipose tissue tumor necrosis factor and interleukin- 6 expression in human obesity and insulin resistance. Am J Physiol Endocrinol Metab 2001; 280: E745-E751.

[7] Tilg H, Hotamisligil GS. Nonalcoholic fatty liver disease: Cytokine-adipokine interplay and regulation of insulin resistance. Gastroenterology 2006; 131: 934-945.

[8] Wernstedt I, Eriksson AL, Berndtsson A, et al. A common polymorphism in the interleukin- 6 gene promoter is associated with overweight. Int J Obes 2004; 28: 1272 1279.

[9] Fishman D, Faulds G, Jeffery R, et al. The effect of novel polymorphisms in the interleukin-6 (IL-6) gene on IL-6 transcription and plasma IL-6 levels, and an association with systemic-onset juvenile chronic arthritis. J Clin Invest 1998; 102: 1369-1376.

[10] Qi L, Zhang C, van Dam RM, Hu FB. Interleukin-6 genetic variability and adiposity: associations in two prospective cohorts and systematic review in 26,944 individuals. J Clin Endocrinol Metab 2007; 92(9): 3618-3625.

[11] Slaughter MH, Lohman TG, Boileau RA, et al. Skinfold equations for estimation of body fatness in children and youth. Hum Biol 1988; 60: 709-723.

[12] Ten S, Maclaren N. Insulin resistance syndrome in children. J Clin Endocrinol Metab 2004; 89(6): 2526-2539. 
[13] Romer T. (red): Leptyna, hormon komórek tluszczowych. Endokrynologia kliniczna dla ginekologa, internisty i pediatry. Springer, PWN, Warszawa 1998; 182-186 (in Polish).

[14] Alberti G, Zimmet P, et al. The IDF consensus definition of the metabolic syndrome in children and adolescents. IDF, 2007. ISBN 2-930229-49-7

[15] Berenson ML, Levine DM, Goldstein M. Intermediate statistical methods and applications, Prentice-Hall, New Jersey, 1983

[16] Hosking L, Lumsden S, Lewis K, et al. Detection of genotyping errors by Hardy-Weinberg equilibrium testing. Eur J Hum Genet 2004; 12: 395-399.

[17] Kelishadi R. Childhood overweight, obesity, and the metabolic syndrome in developing countries. Epidemiol Rev 2007; 3: 1-15.

[18] Katzmarzyk PT, Perusse L, Malina RM, et al. Stability of indicators of the metabolic syndrome from childhood and adolescence to young adulthood: The Quebec Family Study. J Clin Epidemiol 2001; 54: 190-195.

[19] Bastard JP, Maachi M, Tran Van Nhieu J, et al. Adipose tissue IL-6 content correlates with resistance to insulin activation of glucose uptake both in vivo and in vitro. J Clin Endocrinol Metab 2002; 87:2084-2089.

[20] Bennermo M, Held C, Stemme S, et al. Genetic predisposition of the interleukin- 6 response to inflammation: implications for a variety of major diseases? Clin Chem 2004; 50:2136-2140.
[21] Berthier MT, Paradis AM, Tchernof A, et al. The interleukin $6-174 \mathrm{G} / \mathrm{C}$ polymorphism is associated with in dices of obesity in men. J Hum Genet 2003; 48: 14-19.

[22] Lieb W, Pavlik R, Erdmann J, et al. No association of interleukin-6 gene polymorphism (-174 G/C) with myocardial infarction or traditional cardiovascular risk factors. Int J Cardiol 2004; 97: 205-212.

[23] Terry CF, Loukaci V, Green FR. Cooperative influence of genetic polymorphisms on interleukin 6 transcriptional regulation. J Biol Chem 2000; 275: 18138-18144

[24] Dedoussis GV, Manios Y, Choumerianou DM, et al. The Il-6 gene G-174C polymorphism related to health indices in Greek primary school children. Obes Res 2004; 12(7): 1037-1041.

Corresponding author:

Beata Pyrzak, M.D., Ph.D.

Department of Pediatrics and Endocrinology

Medical University of Warsaw

Marszalkowska 24 St.

00-576 Warsaw, Poland

Phone: +48022 5227435

Fax: $\quad+480226214155$

E-mail: b.pyrzak@wum.edu.pl 